\title{
Information technologies and construction sector: Why construction loses competition for innovations to other industries?
}

\author{
Rudolf Faltinsky ${ }^{1}$, and Galina Tokunova ${ }^{1 *}$ \\ ${ }^{1}$ Saint Petersburg State University of Architecture and Civil Engineering, Faculty of economics and \\ management, 190005 2nd Krasnoarmeiskaya st. 4, Russian Federation
}

\begin{abstract}
Over the last 10 years investments into innovation made at the beginning of 2000s resulted in significant growth not only in separate industries but in global economy as a whole. The development of digital technologies significantly reduced the costs of advance technologies, which made them affordable to a wide range of consumers. Using new tools and methods for interaction of social and economic subjects became a real accelerator of rapid growth for some industries such as media, information and communication technologies or finances. However, no significant innovative changes occur in the construction sector despite a generally acknowledged important role in the economy of both separate countries and in global economic processes. The article considers the factors that have an effect on the digital transformation of construction industry, the peculiarities and problems of this process.
\end{abstract}

Construction makes a substantial contribution to different economic and social processes. Construction business presumes cooperation among organizations from various industries encompassing a wide spectrum of society life. In the USA, for example, people on average spend almost $90 \%$ [1] of time within a room. Thus, a building and materials used to construct and finish it have a significant effect on its inhabitants' health and well-being. Moreover, today about 100 million people work in the construction industry worldwide [2]. Housing construction is $38 \%$ of global construction, transport infrastructure and power engineering projects are $32 \%$, commercial premises and buildings are $18 \%$ and industrial facilities are $13 \%$ [3]. It is worth noting the state's role in construction industry, not only as a regulator but as a participant of economic relations. Public procurement amounts to $31 \%$ of the construction market sales in England, 44\% in Germany and massive 57\% in the United States of America [3]. Construction industry is the largest global consumer of resources and raw materials. This branch of economy annually consumes around 50 of global steel production and 3 bln tons of other raw materials [4]. As far as electric power consumption is concerned, $25-40 \%$ of its global generation is consumed within and by buildings [5].

In such countries as USA, Italy, France the construction sector amounts to about $4-5 \%$ GNP, in developing countries such as China its share is about 7-8\% [6]. It is expected that in

*Corresponding author: tgf_1608@mail.ru 
the nearest years the sector will significantly grow and the total income of construction companies will amount to 15 trillion $\$$ by 2025 [2].

Despite an important role played by construction in the global economy, at present there are no innovative digital technologies implemented in the construction sector, requiring upfront investments. The R\&D investments in construction leg behind those made in the other global economy sectors: less than $1 \%$ of companies' revenue. In automotive and aerospace industries this indicator amounts to $3.5 \%$ and $4.5 \%$ respectively [7]. Part of the technologies being implemented in construction comes from other sectors from technological and processing industries and as a result is not accounted for the construction industry. For example, innovations in the timber and wood processing industries, surely, have direct advantages for construction but their R\&D costs are seldom referred to them. If you look at research data by McKinsey\&Company [7] the lack of financing is one of the reasons for low rates of digital transformation within the construction industry. The penetration of digital technology into construction industry as a whole remains at a relatively low level (Fig. 1). 


\section{McKinsey Global Institute industry digitization index; 2015 or latest available data}

Relatively low digitization

Digital leaders within relatively undigitized sectors

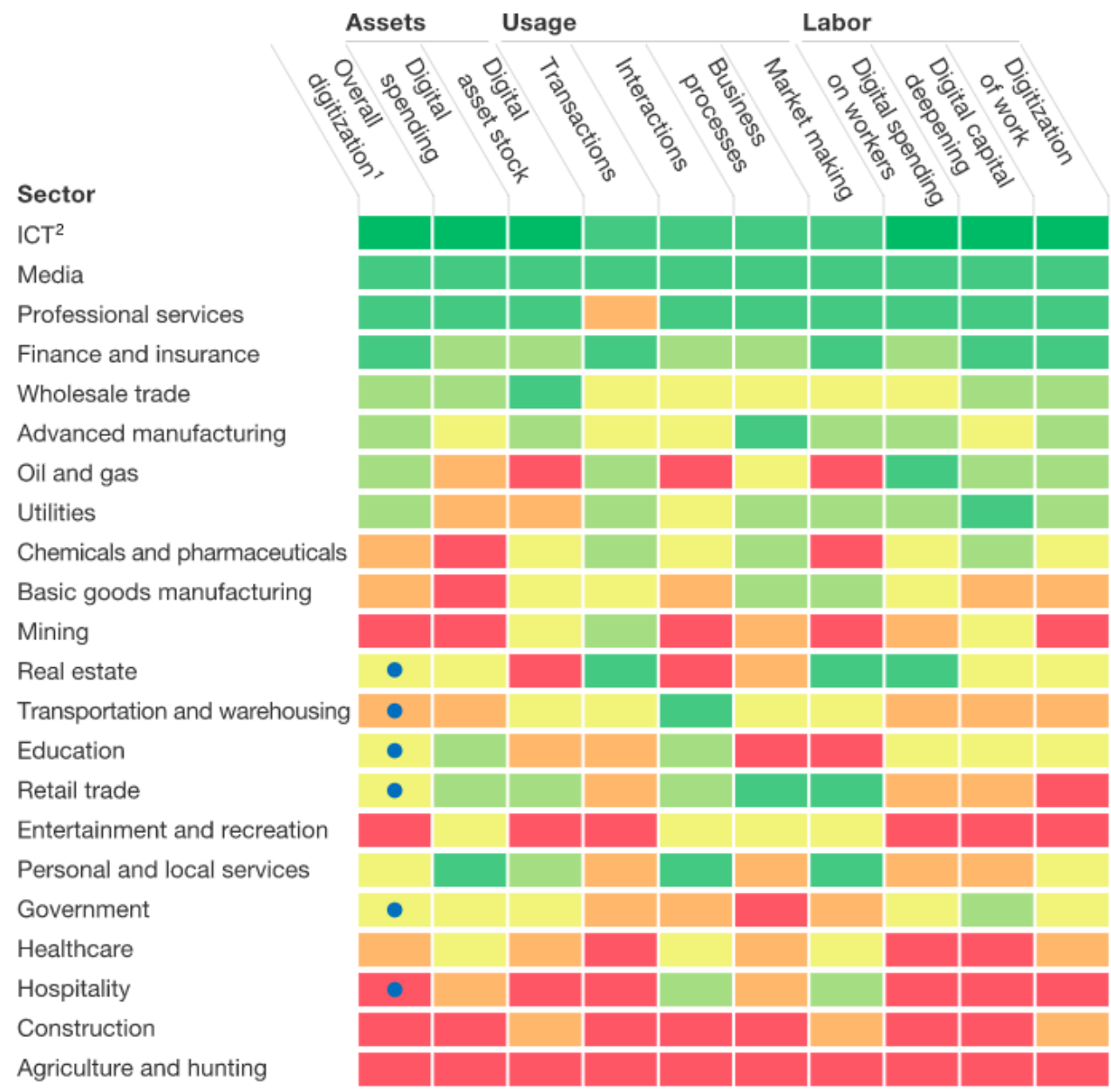

\footnotetext{
${ }^{1}$ Based on a set of metrics to assess digitization of assets ( 8 metrics), usage (11 metrics), and labor (8 metrics).

${ }^{2}$ Information and communications technology.
}

Fig. 1. Level of penetration of digital technologies into different sectors of global economy [7].

Now then most industrial branches have gone through enormous changes over the last several decades and gained from digital and process innovations, the construction sector has not practically utilized the available potential of these transformations. It is one of the reasons why $20 \%$ of construction projects are not completed within timeframes and $80 \%$ of projects exceed their budget [7]. One more indicator of this backlog for innovative transformations in the construction sector that even in such developed countries such as the United Kingdom and Germany there has not been practically labor productivity growth in the construction sector since 1990, however, the GNP shows stable growth in general (Fig. 2). 
Labor productivity, gross value added per hour worked, constant prices, ${ }^{1}$ index: $100=1995$

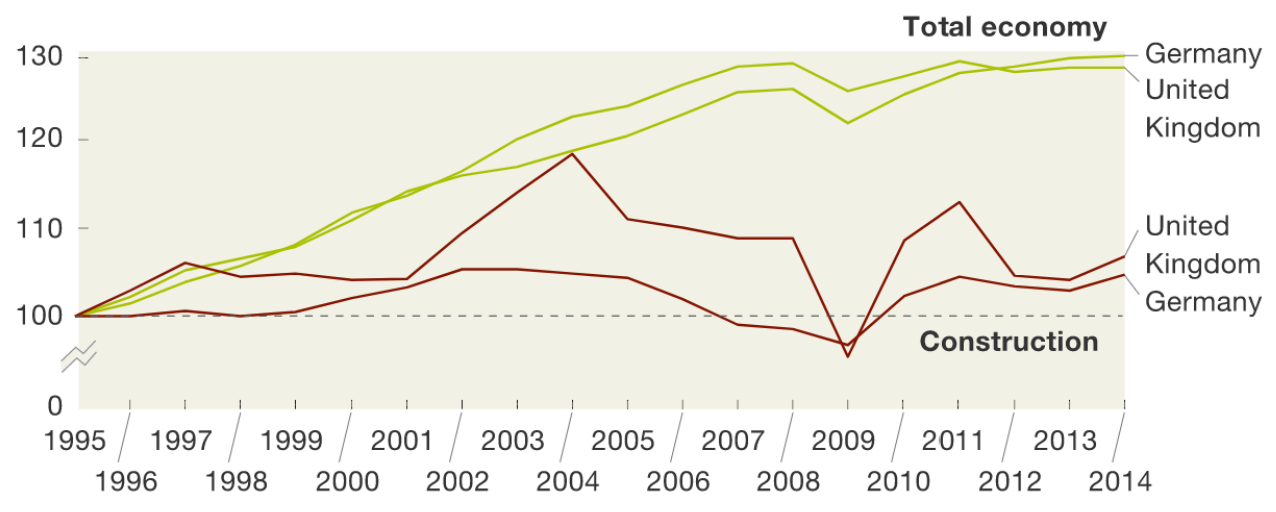

${ }^{1}$ Based on 2010 prices.

Fig. 2. Growth rates of economy and labor productivity in construction [7].

If data from different research works on the level of penetration of digital technologies is compared, for example, conducted by McKinsey\&Company and International comparisons of labor productivity by industry: for 2014, then it is possible to make a conclusion that those sectors, which have implemented advance digital tools and technologies, show much higher relative and absolute indicators of labor productivity. In insurance and financial sectors, information and communications sectors in Italy, Germany and France productivity is 50-60 euro/hour but at the same time this indicator amounts to $20 / 30$ euro/hour in the sphere of construction.

It is impossible to change this situation in the construction sector by introducing several key innovations such as, for example, new high-speed data transmission channels in the telecommunications sector, due to the fact there is a very complicated structure of crossindustry relationships. Integrated digital transformations of all principles, systems and tools of the sector are required.

According to evaluation of the European commission $70 \%$ of innovations in all the industrial sectors are new materials or improved existing ones. Construction materials account for one-third of construction costs that is why they are a rather upcoming trend for development and implementation of innovations. For example, Canadian company Carbon Cure Technologies has developed an innovative technology to enhance the concrete strength by bonding carbon dioxide. This technology will also reduce the amount of harmful emissions into the atmosphere; these emissions are caused by refineries.

Industrial sectors of the global economy, for example, the automotive industry have already reached a breakthrough moment in automation of their manufacturing processes [11], however, the construction industry still has a very low level of automation. At the same time, a significant reduction in costs of key process developments (for example, the cost of unmanned aerial vehicles has dropped by more than 100 times [3]) has become a significant driver for innovations in construction machinery [12]. Equipment has gained a central role in increased productivity, reduced construction costs, reduced lead time, improved quality and reduced risks. The construction of a 57-story building by Broad Group China to innovations implemented in production $90 \%$ of construction work processes have been carried out at the factory, which made it possible to construct the building for 19 days [3].

One the key technologies, that can change the construction sector in the future is $3 \mathrm{D}$ printing. According to specialists of Chinese company WinSun the additive construction 
methods allowed reducing the material consumption twice as much in comparison with the quantities that are usually required during construction of a residential building and the construction time was only the third of what was required during classical approach. All together, the labor costs reduced by $80 \%$, which makes it possible not only to reduce costs and imply lower risk of injury among workers [13].

The development and implementation of digital technologies and processes for operation with big data takes on a central place in transforming the construction industry. These innovations make it possible to create new functional possibility throughout the entire construction project life cycle. According to research conducted by The Boston Consulting Group the large-scale implementation of BIG-data technologies will allow the global economy to save $13-21 \%$ within 10 years annually during construction and $10-17 \%$ during operation of non-residential buildings, which amounts to 0.7-1.2 trillion $\$$ and $0.3-0.5$ trillion $\$$ respectively [14]. Deep implementation of BIG-data technologies entails the infrastructure to be developed for acquisition and transmission of data for processing. The "smart house" or "smart city" ideas become not only the declared principles but practically implemented solutions, which gets to be more affordable due to reduced costs of transmitters, data processing and storage technology as well as information transmission speed. One of the leaders is Singapore that has launched a web-site [15], which can be used by citizens to view some monitoring data and the state authorities, for example, can develop the models of influence exerted by high-rise building being constructed on the wind-flow pattern. A variety of received data makes it possible to enhance the reliability level of reports on current status of objects and forecasts concerning their parameter changes.

Developing tools and technologies for collection, processing and transmission of big data allow building interaction between all construction project participants based on BIM (building information modeling). BIM is a process in which digital information is generated, collected, analyzed and transmitted to all participants accurately and consistently throughout the entire project life cycle starting from survey to dismantling and site return to original state. BIM is a central element of digital transformation of the industry, reflect advantages of all implemented innovations and makes it possible to:

- Control construction process in real time, monitor contractors, trace key indicators and timeframes in any required scale - from strategic level to a certain worker within selected work section;

- Control all design changes, carry out operational recalculation of all indicators while editing a model, including the amount of required materials, labor costs, work completion timeframes, budget.

- Automate all construction machinery control up to automatic adjustment of an operating component (blade, bucket etc) based on design data uploaded in a machine and practically without operator's involvement;

- Simulate different construction scenarios; select an optimal one out of them at predesign stage.

- Receive operational, analytical information providing the customer with relevant data for strategic monitoring and planning at all project implementation stages;

- Calculate site operation and maintenance costs based on collected and combined information received from different sources and data at all construction stages;

- Create contractors database, manage contracts, accounting documentation, construction development programs.

According to research conducted by University of Maryland BIM is capable of reducing costs of design and construction stages by $30 \%$ and $10 \%$ respectively due to implemented innovations. In this case, design costs will decrease by $8 \%$ and construction budget saving will amount to $3 \%$. 


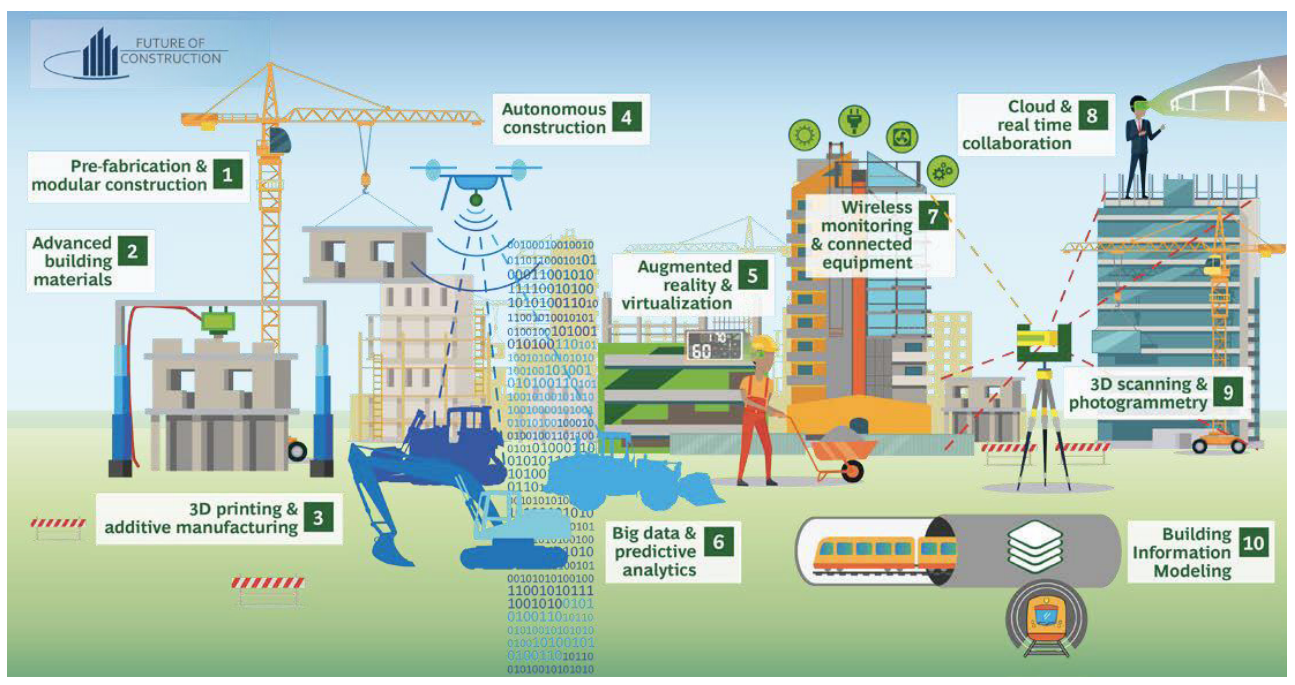

Fig. 3. Key technologies applied in BIM [17].

BIM was originally used only for construction of building but with development of digital technologies and capabilities to process big data at present it is also used in other areas.For example, in the United Kingdom a famous British BIM was launched during implementation of a railway project, which is being implemented in the old part of London and has a complex infrastructure [18]. Finland started implemented its BIM project practically at the same time with the United Kingdom and its experience quickly spread all over Scandinavia and in some time all over Europe. For example, in December 2015 the Federal Ministry of Transport and Digital Infrastructure of Germany published a "road map" for implementation of BIM according to which the information modeling will become an integral part of future government-run infrastructural projects [19]. China should be mentioned in terms of BIM implementation. An average global growth rate of architectures and contractors, who use BIM to run $30 \%$ of their projects amounts to $95 \%$.In China this indicator amounts to $108 \%$. China is among five quick-growing BIM regions along with the United Kingdom, South Korea, Australia and Germany [20]. In Russia the plan for phased implementation of information modeling technologies in the area of industrial and civilian construction was adopted on December 29, 2014 [21] and a "road map" for implementing BIM technologies was approved in April 2017. However, the terms of mandatory information modeling application in implementing state-run projects are not approved yet due to unavailability of digital infrastructure and insufficient human resourcing for its full-scale implementation.

Today the sphere, coverage and geography of projects, which are implemented both with separate innovations, digital tools and with BIM technologies is quite versatile. An increasing technological gap of the construction sector and other branches is a threat for the future development of not only some countries but global economy as a whole. An annual increase in population worldwide, development of global infrastructure will require new large-scale construction projects to be implemented. In this situation the cost and quality parameter requirements will be more demanding due to limited resources. Innovations in construction are not yet widely spread and a gap between innovative leaders and other companies is increasing. Every region and country has its individual peculiarities which have an effect on the level of implementing digital economy elements. In this case it is possible to mention global problems in the construction sector, which force the construction sector to lose completion for innovations to other areas of global economy.

Branch-wise. Construction companies jointly run projects, which have various parameters and properties or jointly implement single projects. Applicable innovative 
solutions are difficult to adapt and use for other projects, which does not contribute to exchange of knowledge, experience and joint developments. The system of tender procedures is not suitable for innovations either. The construction sector is perceived as a production process that runs in accordance with predetermined detailed parameters in implementing a project. Implementing innovations, in other words, changing a project is difficult to put in practice and virtually impossible.

Engineering. Implementing innovative solutions in construction is related with technological risks, which arise both during use of a new material or a technology with historical short-term level of appraisal and during interaction of an innovation with traditional processes and materials [22]. It is quite reasonable that project participants do not want to take construction risks related to engineering solutions that have not been sufficiently timetested and case-recorded.

Market. The key factor of competitive strength in mass consumption segment is price. New properties or improved quality brought by innovations remain to be the secondary factor in demand and quite often not balanced in relation to price. Advance developments are mainly applied in "high" and "elite" construction segments with a relatively small turnover in the construction economy, which does not allow innovative products to be developed from economic point of view [23, 24].

Economic. Innovations often require much higher initial investments, in this case profits are observed throughout the entire project life cycle. For example, most costs to develop a BIM model are incurred during design, whole most advantages from BIM use are obtained by project participants at further stages.

Human resources. Demographic shifts in developed countries lead to an increase in workers' average age within the construction sector. The skill and knowledge requirements tend to be higher, while the education system allowing a sufficient number of specialists to be trained is not implemented.

Legislative. Construction sites and structures form an integral part of society and should provide comfort and what is most important, safe operation. The possible use of innovation, especially in the area of construction materials must be confirmed by appropriate and sometimes many legislative acts, which with an average construction project period equal to 5 years [25] significantly increases the period of their massive implementation.

Due to high capital intensity digital innovations are not the factor forming competitive environment in the construction sector. Innovative activity is perceived as costs but not as required investments into company's development and competitive strength. Problems need to be identified to form a combination of organizational and economic tools to solve these problems and to integrate digital tools or engineering solutions with the investment and construction process.

\section{References}

1. N. E. Klepeis, W. C. Nelson, W. R. Ott, J. P. Robinson, A. M. Tsang, P. Switzer, The National Human Activity Pattern Survey (NHAPS): A resource for assessing exposure to environmental pollutants. Journal of Exposure Analysis and Environmental Epidemiology, 11(3), 231-252 (2001) [online], Available at: [https://www.nature.com/articles/7500165.pdf, date of referencing 01.02.2018]

2. Global Construction Perspectives and Oxford Economics, Global Construction 2025 (2013)

3. World Economic Forum, The Boston Consulting Group, Shaping the Future of Construction. A Breakthrough in Mindset and Technology (2016) [online], Available at: 
[http://www3.weforum.org/docs/WEF_Shaping_the_Future_of_Construction_full_rep ort_.pdf, date of referencing 29.01.2018]

4. World Steel Association, World Steel in Figures 2015 (2015) [online], Available at: [https://aceroplatea.es/docs/WorldSteelFigures2015.pdf, date of referencing 29.01.2018]

5. United Nations Environment Programme, Buildings and Climate Change: Status, Challenges and Opportunities (2007) [online], Available at: [http://hdl.handle.net/20.500.11822/7783, date of referencing 30.01.2018]

6. M. Ishkenova, A brief review of construction sector in the USA, Turkey and EU states (2016) [online], Available at: [http://rfcaratings.kz/wpcontent/uploads/2015/11/Stroitelnyj-sektor-RK-_okt.2016-g..pdf, date of referencing 31.01.2018]

7. R. Agarwal, S. Chandrasekaran, M. Sridhar, Imaginingconstruction'sdigitalfuture (2016) [online], Available at: [https://www.mckinsey.com/industries/capital-projectsand-infrastructure/our-insights/imagining-constructions-digital-future, date of referencing 01.02.2018]

8. A. Ward, A. Kirchherr, P Wales, International comparisons of labour productivity by industry: 2014 (2017) [online], Available at: [https://www.ons.gov.uk/economy/economicoutputandproductivity/productivitymeasur es/articles/internationalcomparisonsoflabourproductivitybyindustry/2014\#results. date of referencing 01.01.2018]

9. L. Probst, E. Monfardini, L. Frideres, S. Moujahid, P. Luxembourg, Smart Living: Advanced building materials (2014)

10. http://info.carboncure.com/xprize-team

11. K. Schwab, The Fourth Industrial Revolution (2017)

12. P. Gerbert, M. Lorenz, M. Rüßmann, M. Waldner, J. Justus, P. Engel, M. Harnisch, Industry 4.0: The Future of Productivity and Growth in Manufacturing Industries (2015) [online], Available at: [http://imagesrc.bcg.com/Images/Industry_40_Future_of_Productivity_April_2015_tcm961694.pdf, date of referencing 01.02.2018]

13. Case Study prepared by the Boston Consulting Group as part of the Future of Construction Project at the World Economic Forum Demonstrating the Viability of $3 D$ Printing at Construction Scale (2016)

14. P. Gerbert, S. Castagnino, C. Rothballer, A. Renz, R. Filitz, Digitalin Engineering and Construction. The Transformative Power of Building Information Modeling (2016) [online], Available at: http://futureofconstruction.org/content/uploads/2016/09/BCGDigital-in-Engineering-and-Construction-Mar-2016.pdf (2018)

15. https://www.onemap.sg/main/v2/ (2018)

16. K. Parvan, Estimating the Impact of BIM Utilization on Building Project Performance [online] Available at: http://hdl.handle.net/1903/13063 (2012)

17. World Economic Forum, The Boston Consulting Group, Shaping the Future of Construction. An Action Plan to Accelerate Building Information Modeling (BIM) Adoption [online], Available at: http://www3.weforum.org/docs/WEF_Accelerating_BIM_Adoption_Action_Plan.pdf (2018)

18. Standard BS 1192:2007+A2:2016,Collaborative production of architectural, engineering and construction information - Code of practice (2007) 
19. Federal Ministry of Transport and Digital Infrastructure: Road Map for Digital Design and Construction - Introduction of modern, IT-based processes and technologies for the design, construction and operation of assets in the built environment (2015) [online], Available at: [https://www.bmvi.de/SharedDocs/EN/publications/road-map-for-digitaldesign-and-construction.pdf?_blob=publicationFile, date of referencing 01.02.2018]

20. Dodge Data \& Analytics, The Business Value of BIM in China http://images.marketing.construction.com/Web/DDA/\%7B43cf3d41-46b5-4413-8aea40d30e7ac57f\%7D_EN_Business_Value_of_BIM_In_China_SMR.pdf (2015)

21. Implementation plan of staged information modeling technologies in the area of industrial and civil construction approved by order of the Ministry of construction and housing and utilities infrastructure of the Russian Federation N 926/пр dated December 29, 2014 (2014)

22. E. U. Elkina, West Irkutsk State Technical University, Latent risks in innovative development and reduction in quality control during investment projects in housing construction, 9 (92) (2014)

23. F. M. Bass, T. V. Krishnan, D. Jain, Marketing Science, Why the Bass Model Fits Without Decision Variables, 13 (Summer) (1994)

24. A. A. Alexeev, Economy and National economy management, Engineering innovation mechanisms in construction 10(131) (2015)

25. Information-analytical agency INFOLine,200 largest construction projects of shopping centers in RF. 2015-2018 projects (2015) 